\title{
Los Mapuche y las lucha por la autonomia en Chile, 1990-2005
}

\section{Mapuche and the struggle for autonomy in Chile, 1990-2005 \\ Pedro Canales Tapia*}

\begin{abstract}
Resumen
El presente trabajo se detiene en la historia y discursividad del movimiento mapuche en Chile durante las dos últimas décadas. En este sentido, esta propuesta posee como marco teórico el debate respecto del colonialismo y los procesos de descolonización en América Latina; y en términos metodológicos, esta investigación elabora su análisis desde el método histórico y la crítica de fuentes.
\end{abstract}

Palabras claves: Movimiento mapuche - autonomía - Estado chileno descolonización.

\begin{abstract}
This work focuses in history and discourse of the Mapuche movement in Chile over the last two decades. In this sense, this proposal has as theoretical framework the debate on colonialism and decolonization processes in Latin America; and methodological terms, this research draws its analysis from the historical method and source criticism.
\end{abstract}

Keyword: Mapuche movement - autonomy - Chilean State - decolonization.

\section{Resumo}

Este trabalho pára na história e discurso do movimento Mapuche no Chile ao longo das últimas duas décadas. Neste sentido, a presente proposta tem como referencial teórico o debate sobre os processos de colonialismo e descolonização na América Latina; e termos metodológicos, esta pesquisa chama a sua análise do método e fonte de crítica histórica.

Palavras-chave: Movimento Mapuche - Autonomia - Estado chileno descolonização.

${ }^{*}$ Doctor em Estudios Latinoamericanos. Académico e investigador post doctorado de Instituto de Estudios Avanzados, Universidad de Santiago de Chile. Docente de Universidad Viña del Mar. E-mail: pedro.canales@ usach.cl; pcanales@uvm.cl 


\section{Introducción: La ocupación del territorio Mapuche}

Luego de 1883 la región de la Frontera, hoy región de la Araucanía, al sur de Chile, comenzó a evidenciar transformaciones radicales en su paisaje ancestral. De partida, la autonomía al sur del río Bío-Bío pasó a ser sólo un recurso nostálgico de antaño ${ }^{1}$. La autoridad chilena se posesionó de este espacio anhelado desde la década de $1850^{2}$. El ingreso de colonos fue abriendo nuevas fisonomías en arquitectura, industria y agricultura. La locomotora ingresó con la inauguración del viaducto del Malleco hacia 1890. Las imágenes, estereotipos e ideologías fueron la interlocución válida y extendida entre la población no mapuche que posaba de europea, como ha planteado Patricio Vergara en Temuco $^{3}$. Holdenis Casanova en torno este punto comenta que "La imagen es, pues una construcción sociocultural que se define en su articulación con el grupo y su contexto global”, lo que “(...) explica, por ejemplo, el enorme contraste existente entre la llamada visión, imagen y versión de los vencidos y de los vencedores en relación al proceso de conquista de América"4.

Milán Stuchlik en 1985 sostenía que por medio de la estereotipación de la población mapuche, la esfera no-mapuche o wingka siempre intervino en el quehacer y dinámica de este pueblo. Para este autor, el estereotipo “(...) se modifica no tanto con los cambios mismos de la cultura mapuche, sino más bien con los que ocurren en la cultura chilena"'5.

El autor antes citado plantea que cada época de la historia de Chile se acompaña de un discurso indígena, a veces proclive hacia los indígenas y a veces no. De ahí, indica el antropólogo, las imágenes de heroísmo mapuche en tiempos coloniales y las de bárbaro, holgazán y pagano en tiempos republicanos. El primer estereotipo afianzó el ejemplo libertario de los grupos dirigentes que llevaron a cabo el proceso emancipatorio desde 1810;

${ }^{1}$ CANIUQUEO, Sergio. Dictadura y pueblo mapuche 1973 a 1978. Revista de historia social y de las mentalidades. USACH, Chile. № 17, 2013.

${ }^{2}$ PINTO, Jorge. La ocupación de la Araucanía en el siglo XIX ¿Solución a una crisis del modelo exportador chileno? Revista Nütram. Chile. Año VI, № 3, 1990 (A).

${ }^{3}$ VERGARA, Jorge y ARAVENA, Andrea. La visión del conflicto a través de la prensa. En Las tierras de la ira. Disponible en: File://A:/Tierra.Html. 2000, pp, 12-13.

${ }^{4}$ CASANOVA, Holdenis. La Araucanía colonial: discursos, imágenes y esteretipos (1550-1800) en PINTO, Jorge. Del discurso colonial al proindigenismo. Temuco: Ediciones Ufro. 1996. pp. 42-43; CASANUEVA, Fernando. Indios malos en tierras buenas en PINTO, Jorge. Modernización, inmigración y mundo indígena. Temuco: Ediciones Ufro, 1998, p. 43.

${ }^{5}$ STUCHLIK, Milan. Rasgos de la sociedad mapuche contemporánea. Chile. Editorial Universitaria, 1974, p. 28. 
el segundo permitió ingresar en la Araucanía, anexarla al territorio chileno y reducir a sus antiguos habitantes ${ }^{6}$.

En este mismo ámbito, José Bengoa sostiene que la violencia interétnica surge de la intolerancia encubada por la sociedad criolla que da la espalda a su acerbo indígena ${ }^{7}$. Rolf Foerster por su parte sostiene que los Mapuche reprodujeron, hasta hoy inclusive, la violencia contra el hombre no-mapuche debido a la cosmovisión de la eterna deuda ${ }^{8}$, es decir, la convicción de que la violencia desplegaba contra los mapuche de antaño no puede ser saciada por algo que no sea la violencia contra agresores.

Volviendo a Bengoa, este reconoce que el conflicto fue y es evidente 9 . Apuntando que: "En las pantallas de televisión hemos visto a mujeres mapuche golpear a funcionarios del Estado; se ha visto una larga marcha caminando desde el sur a Santiago y también escenas con altos contenidos de violencia", afirmando que "Hay una larga historia de conflictos" de conflictos se fue tejiendo poco a poco desde el valle central ${ }^{11}$. La Araucanía, iniciada la segunda mitad de la centuria decimonónica, retomó la importancia económica de antaño. Revisemos.

Hasta el triunfo mapuche de Curalaba, este espacio fue de vital importancia para la colonia hispana radicada en Santiago y sus alrededores. Rica en lavaderos de oro y plata, esta región proliferó en pueblos y fortines que fueron expresando la intención del español de asentarse en la zona. No obstante, luego de 1598 todo cambió. Los asentamientos humanos fueron destruidos y asolados por los Mapuche. Los lavaderos corrieron la misma suerte. El río Bío-Bío se constituyó en frontera natural. Los colonos crearon el ejército permanente utilizando el Real Situado ${ }^{12}$ como mecanismo de financiamiento. Los encomenderos del valle central no querían volver al sur.

El territorio mapuche de la Araucanía fue desocupado por el contingente hispano. Sólo tras la dictación de la Cédula Real de 1609 que permitía capturar indígenas alzados o sorprendidos con armas hizo recobrar en parte el interés

\footnotetext{
${ }^{6}$ STUCHLIK, Milan. Las políticas indígenas en Chile y la imagen de los mapuches. Revista CUHSO. Vol. II. № 2, 1985. ${ }^{7}$ BENGOA, José. Historia del pueblo mapuche. Chile: Ediciones Sur, 1987 (A).

${ }^{8}$ FOERSTER, Rolf. Introducción a la religiosidad Mapuche. Santiago: Editorial Universitaria, 1991.

${ }^{9}$ BENGOA, José. Emergencia indígena en América Latina. Chile: FCE, 1999, p. 13 (B).

${ }^{10}$ Ibídem.

${ }^{11}$ PINTO, Jorge. Del antiindigenismo al proindigenismo en Chile en el siglo XIX en PINTO, Jorge. Del discurso colonial al proindigenismo. Temuco: Ediciones Ufro, 1996, pp. 83-84 (B).

${ }^{12}$ Real Situado: impuesto de la corona española con el cual se financió el ejército profesional de la Frontera luego de la derrota militar española en batalla de Curalaba(1598), sur de Chile. Para los mapuche este territorio es Wallmapu, el "país mapuche".
} 
por la Araucanía, pero ya no como espacio de radicación sino tan sólo como centro de captura de "piezas" ${ }^{13}$ y tráfico de esclavos ${ }^{14}$. Aparte de este interés nada movió a los inmigrantes a retomar interés por las tierras Mapuche.

Las guerras hispano-mapuche durante la colonia, guerras fronterizas dice Fernando Casanueva, en el siglo XVII definieron un cuadro poco grato entre los bandos contrarios, motivo por el cual el testimonio presente en el Cautiverio de Núñez de Pineda y Bascuñan asume ribetes de "extraordinario", pues dichos conflictos de acuerdo con el autor antes nombrado fueron: "(...) una verdadera <<caza de indios>>, quienes eran vendidos como mano de obra esclava a los hacendados del norte del Bío-Bío e incluso en el Perú" ${ }^{15}$.

Propia de una mentalidad europea de "reducción" de lo indígena según plantea Martín Lienhard, cuando sostiene que una de las prácticas simbólicas del hombre americano prehispánico, la voz y su discurso, fueron interceptadas por el escritor no-indígena, ya que los discursos: “(...) transcritos, en efecto, no suelen "representar" sino la fracción de los que pueden servir, de algún modo, para "mejorar" la organización de la Colonia", los otros “(...) en su mayoría, no entrarán a formar parte de la memoria letrada "occidental". Sobre ellos se tenderá el velo del silencio (...)"16.

Advierte el historiador. Sosteniendo, por otro lado, la investigadora argentina, María Mercedes González Coll mediante un modelo de análisis fronterizo, que tanto para el caso trasandino como chileno el indígena resultó ser un sujeto negado social, política y económicamente, generando esto un armazón complejo, puesto que la inestabilidad e imprevisibilidad: “(...) sumada a la conflictiva fricción de la cultura de contacto, hacen que la vida cotidiana de los diversos actores hayan sido extremadamente violenta"17.

El debate entre Leonardo León y Sergio Villalobos resultó preocupante en su momento, respecto a la vigencia o no luego del año 1600 de la Guerra de Arauco. Para el primer autor, dicha guerra no cesó luego del hito temporal estipulado, a diferencia de lo planteado por el otro experto, sino que sólo experimentó un proceso de transformación que derivó en un cúmulo de nuevas

\footnotetext{
${ }^{13}$ JARA, Álvaro. Guerra y sociedad. Chile: Editorial Universitaria, 1971, pp. 20-22.

${ }^{14}$ Ibídem, pp. 20-22.

${ }^{15}$ CASANUEVA, op. cit., p. 43.

${ }^{16}$ LIENHARD, Martín. El cautiverio colonial del discurso indígena: Los testimonios en PINTO, Jorge. Del discurso colonial al proindigenismo. Temuco: Ediciones Ufro, 1992, pp. 10-11.

${ }^{17}$ GONZALEZ, Karina et al. La política de criminalización del movimiento mapuche bajo el sexenio de Lagos en YAÑEZ, Nancy y AYLWIN, José. El gobierno de Lagos, los pueblos indígenas y el "nuevo trato". Chile: Ediciones Lom, 2007, p. 130.
} 
expresiones histórico-sociales como el maloquero y los conchavadores ${ }^{18}$. En definitiva, según León, la Guerra de Arauco dejó de lado los tildes epopéyicos y heroicos propios de La Araucana de Ercilla y se expresó a través de lo que el autor denomina una Guerra Chica, indicando: “(...) desde comienzos del siglo XVII, los guerreros indígenas abandonaron el antiguo sistema de guerra fortificada y adoptaron nuevas tácticas de confrontación", consignando que “(...) el conflicto hispano-indígena no desapareció” sino que “(...) fue reemplazado por la furia del guerrero del malón que, montando en excelentes caballos, cubiertos de coseletes y armado de cuchillos, asolaba las haciendas y villas"19.

Jorge Pinto ha planteado que la Ocupación Militar de la Araucanía, expresión de máxima violencia chilena en contra de conglomerados étnicos en lo que va de la historia republicana nacional, fue tan bien ordenada, orientada y propulsada, que llegó a tener en sus cimientos el respaldo potente de una ideología que él denominó Ideología de la Ocupación. Dicho cuerpo ideológico, carente de una reflexión profunda o un sentir que no fuera una evocación chauvinista del ser chileno, se erigía en cuatro postulados elementales, todos ellos contra-mapuche e impulsores ciertos de un acto, para sus forjadores, patriótico y moral, como lo era anexar las tierras al sur del Bío-Bío a la nación. Pinto describiendo dicha ideología, sostiene:

\begin{abstract}
“En primer lugar, se insistió en la necesidad de sentar soberanía en todo el territorio nacional (...). En segundo lugar, se recurrió a la idea de que el indígena pertenecía a una especie de raza inferior, a la cual había que tratar sin muchas consideraciones. (...) Los bárbaros acosaban a Chile. Ese fue el tercer argumento. (...). Los mapuche fueron mostrados como un grupo que ponía en peligro al país. (...). Por último, se planteó que la ocupación de la Araucanía no podía ser sólo tarea de chilenos (...), requería de individuos de temple especial: lo inmigrantes europeos" 20 .
\end{abstract}

Concluyendo este autor que no era menester solamente ocupar el territorio mapuche sino que, por consenso, correspondía tecnologizar dicha acción: “(...) había que extender hasta su territorio el Chile que estaba más allá de sus fronteras y para lograrlo, había que plantar los postes del telégrafo,

\footnotetext{
${ }^{18}$ LEON, Leonardo. Maloqueros y conchavadores en la Araucanía. Temuco: Ediciones Ufro, 1990, p. 15.

${ }^{19}$ Ibidem.

${ }^{20}$ PINTO, Jorge. Morir en la frontera en ORTEGA, Luis (edit) La guerra civil de 1891. Chile: Ediciones Usach, 1992, p. 137 (C).
} 
llevar a cabo obras de infraestructura que optimizaran la producción agrícola, y sobre todo, instalar el ferrocarril"21.

Sin duda alguna, fueron las constantes crisis del sistema monoexportador chileno a mediados del siglo XIX, las que instaron al Estado -movido por empresarios como José Bunster desde Valparaíso, e incitados pública y masivamente por periódicos como El Ferrocarril de Santiago y El Mercurio del puerto citado-, a mirar cada vez con más recurrencia hacia el sur, hacia las tierras mapuche de la Wallmapu (Pinto, 1996): “(...) el indígena pasó a segundo plano; lo que interesó entonces fueron sus tierras. La vieja conquista dio paso a una invasión que se tradujo en un desenfrenado proceso de usurpación de territorios"22.

Señala Pinto.El mapuche fue concebido por el positivismo decimonónico como el enemigo directo del progreso y el orden. Benjamín Vicuña Mackenna, en 1868 decía sobre el mapuche, que éste era un bárbaro: “(...) bruto indomable, enemigo de la civilización, porque sólo adora los vicios en que vive sumergido" 23 .

Diego Barros Arana, en la misma frecuencia, califica en sus escritos a los mapuche, de salvajes, bárbaros. Primitivos, holgazanes y brutos; presos de la barbarie, en la cual todos: “(...) desempeñan las mismas ocupaciones, todos son guerreros, cazadores, constructores de chozas y de embarcaciones y aun agricultores, así como todos eran guerreros" ${ }^{24}$, según escribe un estudio de Fernando Casanueva.

El ejemplo más radical en sus apreciaciones lo entregó Crescente Errázuriz, quien declaró que los mapuche eran diferentes y formaban otra raza, especialmente cuando recuerda que por ser hijos de conquistadores o colonos los descendientes de raza latina se diferencian claramente del Mapuche de la frontera ${ }^{25}$. Pinto puntualiza lo siguiente: "Siguiendo la manera de hablar entonces usada -señala-, que facilita mucho la narración, llamamos españoles no sólo a los que por su origen lo era, sino también a los criollos descendientes de los conquistadores", que "En contraposición a los indios, llevaban en toda América el nombre de españoles los hijos de la raza latina que obedecían al rey de España"26.

\footnotetext{
${ }^{21}$ Ibidem, p. 137.

${ }^{22}$ PINTO, op. cit., p. 36 (B).

${ }^{23}$ Ibidem, p. 99.

${ }^{24}$ CASANUEVA, op. cit., pp. 70-71.

${ }^{25}$ PINTO, Jorge. El estado chileno, la nación y los mapuche. Chile: Ediciones IDEA, 2001, p. 140 (D). ${ }^{26} \mathrm{Ibidem}$.
} 
Cuando el siglo XIX expiraba, la Araucanía experimentaba grandes cambios. Uno de los más peculiares fue sin duda la violencia, ya no de los mapuche ni del ejército de la Ocupación, sino que propio del bandolerismo. Violencia al fin y al cabo. Expresión de desajustes postocupación: "En palabras de Encina -expresa Pinto-, la región se había convertido en un hervidero humano, saturado de buhoneros, aventureros en busca de fortuna, abogados, tinterillos y, entre ellos, bandidos y cuatreros que provocaban desolación" 27 .

A lo que se adhería la feracidad del paisaje regional, imán para sujetos en conflicto con la justicia, la familia o algún patrón explotador, por citar ejemplos. Recuerdo innato de los bosques de Sherwood según el autor. Recientemente Leonardo León ha publicado Araucanía: la violencia mestiza y el mito de la "pacificación", en el cual sostiene que luego de la Ocupación, el mayor obstáculo para consolidar dicho despojo fue la violencia mestiza. Dice al respecto: "En efecto, si los mapuche fueron finalmente forzados a aceptar la imposición de la institucionalidad huinca (extranjera) sobre sus tierras, la resistencia de la población mestiza a la expansión fue mucho más violenta y tenaz"28.

Los mapuche que sobrevivieron a la guerra de exterminio lidiada con su contra entre 1870 y 1883, fueron "acorralados" en "reducciones" bajo el amparo legal de los Títulos de Merced entregados por la Comisión Radicadora de Indígenas que pasó por tierras australes mensurando y entregando estos documentos a los loncos o jefes locales. La ley que permitió normar el proceso de Radicación fue promulgada el 4 de Diciembre de 1866. Paulina Maturana la describe como un cuerpo legal referido: “(...) a la fundación de ciudades en el territorio de los indígenas y a la enajenación de propiedades de estos. La ley también regula lo referido a la enajenación y disposición de tierras del Estado y a su adquisición por particulares" ${ }^{29}$. Siendo reemplazada en 1874 por otra ley, derogando la institución del protectorado de indios y la comisión de ingenieros, reemplazada por un magistrado asentado en la corte de Apelaciones de Concepción. Sólo en 1883 la ley de radicación, con enmiendas y todo, pudo comenzar a cumplir su objetivo. Hasta 1929 se desarrolló este proceso.

Los títulos de Merced inscritos durante estos años en el Registro Conservatorio Especial para la Propiedad Indígena, fueron 2.918, quedando vastas zonas sin ser visitadas por esta comisión, especialmente en Valdivia

\footnotetext{
${ }^{27}$ PINTO, op. cit., p. 139 (C).

${ }^{28}$ LEON, Leonardo. Araucanía: la violencia mestiza y el mito de la "pacificación”. 1880-1900. Chile: Ediciones UARCIS. 2005, p. 9.

${ }^{29}$ MATURANA, Paulina. 1990, p. 35.
} 
y Osorno, es decir, a 75.000 mapuche. Los mapuche que sí fueron radicados fueron 82.629 , en un territorio aproximado de 510.386 hectáreas, equivalentes a 6,18 hectáreas por persona ${ }^{30}$. El ancestral territorio mapuche de más de cinco millones de hectáreas fue también reducido. No quedó para los mapuche más que el 6,3\% de su antiguo territorio o butalmapu.

Pasadas las décadas ¿Cuál ha sido el tinte que ha adquirido esta relación entre estado y pueblo Mapuche? ¿Cuáles han sido las permanencias y cuales los cambios que se vislumbran?

\section{Estado criminalizador, pueblo movilizado}

Luego de más de cien años, el Estado chileno se ha presentado -iniciado el siglo XXI- frente a la población Mapuche en situación de movilización y reivindicación territorial - cultural - política, de manera arbitraria, recelosa y jurídicamente irascible. En palabras de Karina González, Eduardo Mella y Rodrigo Lillo: "Un balance de las políticas indígenas durante el gobierno de Ricardo Lagos no puede soslayar la política de "criminalización" impulsada por dicha administración y destinada a desarticular a organizaciones y comunidades mapuche que habían tomado parte en una serie de movilizaciones desde fines de los 90 y a través de las cuales se expresaron demandas de restitución de tierras usurpadas" ${ }^{31}$. Ya no será por medio del soldado de la Frontera, el misionero capuchino, el comisionado de radicación o el Juez de Indios que se contactará con este pueblo. Durante estos lustros el contacto comenzó a ser por intermedio del Juzgado de Garantía, dentro de un radio mayor de Reforma Judicial, denominado en el ocaso de la centuria XX como la reforma del siglo y con un marco jurídico punitivo denominado ley anti terrorista.

Las informaciones emanadas de los medios de comunicación tanto nacionales como extranjeros daban cuenta iniciado este siglo, de una delicada y enrarecida coyuntura étnico-política en las regiones del Bío-Bío y la Araucanía. Analicemos niveles y ámbitos comprometidos.

En el ámbito social, las comunidades mapuche rurales y las organizaciones urbanas fueron golpeadas fuertemente por la muerte del joven mapuche Alex Lemün a fines del 2002, en el fundo Santa Elisa propiedad de forestal Mininco. Si bien en términos oficiales aún no hay claridad de lo sucedido la tarde del 7 de Noviembre en la comunidad Montutui Mapu, comuna de Ercilla, la alta

\footnotetext{
${ }^{30}$ MOLINA, Raúl. La defensa de la tierra en el siglo veinte. El pueblo mapuche. Revista El Canelo. La otra historia. № 2, 1992, p. 46.

${ }^{31}$ GONZALEZ et al, op. cit., p. 59.
} 
jerarquía de Carabineros reconoció que el proyectil que acabó con la vida de Lemün pertenecía a la institución uniformada. Hoy el caso descansa en los archivos de la fiscalía militar de Valdivia.

Luego de dicha noticia de sangre, los mapuche radicalizados y dolidos por este suceso, aseguraron iniciar una escalada de hechos de violencia en respuesta a la conducta del Estado chileno, claramente represor y responsable del curso de acontecimientos peligrosos para la convivencia nacional en pleno.

Atentados incendiarios en Collipulli, Ercilla y Lumaco principalmente, fueron la voz de alerta en un contexto enrarecido por la prensa regional que marcando diferencias entre no-mapuche y mapuche, resaltó noticias de segundo orden durante esos días con la clara intención de no informar o hacerlo levemente sobre este grave incidente (atentado y muerte). Hacerlo implicaba resaltar la muerte del joven comunero de Malleco. Para la prensa local, la muerte de Lemün fue un asunto delictual, propio de las paginas rojas, parte integrante de una historia escrita antes de que ocurriera; incuestionable y peligrosa en cuanto comprometía -de forma retórica por lo demás- la seguridad de los chilenos inocentes y de los mapuche que quieren progresar en paz, ajenos a todo conflicto, según la semántica de la prensa.

Políticamente, en palabras de José Aylwin y de los obispos de la zona sur $^{32}$, los mapuche movilizados, al ser procesados por la justicia chilena dentro de una lógica también chilena, fueron "criminalizados"33. Este proceso histórico es reciente, si bien no es primera vez que por medio de la ley chilena, éstos han sido cuestionados, procesados o enjuiciados. La diferencia radica en que en la actualidad, con esta tendencia criminalizadora, la autoridad confía en desenraizar las demandas mapuche y sus actores permanentes del discurso público y dar por hecho -a partir de esta medida- el carácter ilícito y punitivo de estas aspiraciones. Según González, Mella y Lillo, la política de criminalización del movimiento mapuche se amparó en una política sostenida en la persecución y desarticulación de las cúpulas indígenas. De acuerdo con estos autores:

"Dicha política se tradujo en la aplicación de la ley Antiterrorista para reprimir al movimiento mapuche, y a sus respectivos dirigentes. El objetivo: resguardar la soberanía nacional, supuestamente amenazada por las acciones de protesta

\footnotetext{
${ }^{32}$ AYLWIN, José. La política del "Nuevo Trato": antecedentes, alcances y limitaciones en YAÑEZ, Nancy y AYLWIN, José. El gobierno de Lagos, los pueblos indígenas y el "Nuevo trato”. Chile: Ediciones Lom, 2007.

${ }^{33}$ MELLA, Eduardo. Los mapuche frente a la justicia chilena. Chile: Ediciones Lom, 2007; CORREA, Martin y MELLA, Eduardo. Las razones del Ilküm/Enojo. Chile: Ediciones Lom, 2010.
} 
a través de las cuales el movimiento social mapuche ha ejercido presión en las autoridades para exigir respuesta a sus reivindicaciones de tierras"34.

En otro ámbito, la prensa regional de la Araucanía, ahora sí, informaba con evidente conformidad, en diciembre de 2002, de la "desarticulación" de los focos violentistas al interior del movimiento mapuche, con la detención de 15 dirigentes de la Coordinadora Arauco-Malleco y un empresario que sospechosamente hasta antes de 1973 se ligó con el grupo paramilitar denominado "Patria y Libertad", como colaborador de los hechos imputados.

Tanto la prensa escrita como televisiva se describió en extenso el detalle de la operación que "redujo" a este grupo de mapuche, surgiendo voces disidentes que acusaron a la fiscalía local de no poseer suficientes pruebas, más que un par de consignas escritas en un muro y algunos dibujos incitando a la subversión, como para acusar de forma tan categórica a dichos dirigentes. Durante la primera quincena de Enero de 2003 se presentó de la misma manera la condena de los hermanos Pichún Collonao acusados de quemas de un camión forestal en abril de 2002.

Con la criminalización de las demandas y reivindicaciones mapuche comenzaron a surgir interrogantes y bisoñas alteraciones en el tratamiento de la temática indígena en general y mapuche en particular. Por un lado, se cuestiona la validez de las prerrogativas indígenas y se las reduce a un mero discurso ideológico que pretende alcanzar grados de autonomía como respuesta "sin basamento" a la política estatal de asimilación total durante los últimos 193 años de vida republicana al norte del río Bío-Bío. Por otro lado, el Estado chileno articula velozmente políticas sociales potentes y con fuerte respaldo de entidades financieras internacionales, nuevos cargos políticos a cargo de la situación, reformulación de CONADI y una Comisión de alto rango denominada de Verdad y Nuevo Trato, presidida por el ex presidente Patricio Aylwin. Cada uno de estos mecanismos de apoyo y/o acercamiento con la sociedad mapuche reviste procesos de iniciación de acuerdos, cercanías, lenguajes y confianzas. Con ello se ha lanzado por la borda la historia de contactos entre la autoridad chilena y los mapuche, acuñada durante esos años por los gobiernos de la Concertación ${ }^{35}$.

Económicamente, la situación mapuche es lamentable, si bien existen intentos neoliberales por parte del Estado chileno por revertir esta situación, la variable histórica reconoce ciertas lecturas antes de intentar resolver esta

\footnotetext{
${ }^{34}$ GONZALEZ, et al, op. cit., p. 59.

${ }^{35}$ GONZALEZ et al, op. cit.
} 
cuestión. Para los expertos en Historia de la Araucanía, José Bengoa entre otros, la característica más visible de la relación Estado-sociedad mapuche es:

“(...) además de la situación bélica y la mortandad de todos conocidas, fue y ha sido la negación de las sociedades indígenas. Las sociedades latinoamericanas, sus Estados nacionales se levantan sobre la negación de <<lo indígena >>. El no reconocimiento conduce a la discriminación, y ésta a la marginalidad, y la pobreza" ${ }^{\prime 36}$.

Luego de 1883, este proceso de pauperización radical de la estructura productiva mapuche, comenzó a activar lo que hoy conocemos como los más altos y preocupantes índices de pobreza y marginalidad a nivel nacional. En este orden argumental, Bengoa pregona desde hace años el "desarrollo con identidad" en su calidad de investigador, profesor, director de CEPI, y como rector. Al respecto sostiene:

“(...) en los Pueblos Indígenas de carácter minoritario, esto es, ubicados físicamente en sociedades mayores, es necesario, se requiere, de un estatuto aprobado por el conjunto de la sociedad" (...) pretensión traducible en "(...) reconocimiento de la diversidad étnica y el derecho a la participación y la decisión autónoma en las definiciones que le competen en el ámbito del desarrollo" ${ }^{\prime 3}$.

Esgrimiendo durante el año 2000, que las políticas sociales relativas a los mapuche deben, para sufrir efectos favorables, apuntar hacia cinco puntos relevantes: Políticas de reconocimiento de derechos colectivos; política institucional coherente en aquellas que lo ameriten; política de inversión y proyección permanente y sistemática; políticas de complementación agraria y forestal, y políticas multiculturales ${ }^{38}$. De otra manera, advierte, el trabajo en este sentido seguirá siendo errático y contradictorio.

José Aylwin en 1995 argumentaba acerca de este mismo asunto, que las indicaciones a escala mundial estaban cambiando, pues:

"Las tendencias integracionistas que caracterizaron las políticas y legislaciones
impulsadas en gran parte del mundo hasta mediados de siglo, en base a las que
se propiciaba la incorporación progresiva de estos pueblos y sus integrantes
a las culturas y formas de desarrollo de las sociedades globales, han sido
sustituidas por otras basadas en el reconocimiento de la especificidad y aportes
de estos pueblos, así como el reconocimiento a los últimos de una serie de

\footnotetext{
${ }^{36}$ BENGOA, op. cit., p. 17 (A).

${ }^{37}$ BENGOA, op. cit., p. 21 (A).

${ }^{38}$ Ibídem, pp.123-125.
} 
derechos económicos, sociales, culturales y políticos que hasta hace poco les habían sido desconocidos"39.

Ahora bien, durante el siglo XX, el movimiento mapuche en este sistema de relaciones, dispositivos y prioridades fue hilvanando diferentes agrupaciones y semánticas de lucha que hicieron frente a esta actitud del Estado. Hubo durante dicho siglo por ejemplo, organizaciones mapuche permeadas por todos los colores y espectros políticos no-mapuche. El partido Democrático Nacional, la democracia cristiana, los socialistas, comunistas, el MAPU y el MIR ${ }^{40}$. La represión militar post 1973 evidencia el alto compromiso político winka de los mapuche.

José Marimán sostiene en esta discusión, que en el fondo de la lucha mapuche pareciera estar:

“(...) la percepción de la discriminación en su contra como pueblo, de lo propio -lo diferente - es motivo de desprecio y cuando no de persecución. Discriminación que puede tomar formas políticas, económicas, sociales o culturales. Discriminación que deviene directamente de su situación de población derrotada y dominada por otra. Derrota y dominación se presentan agravadas en el caso mapuche, por la colonización de la cual fue objeto la nación mapuche" ${ }^{41}$.

Así, para este autor, en un análisis comparativo, esto no sucedió con el pueblo vasco, a quienes el Estado de España ha oprimido nacionalmente pero no ha colonizado. Agregando que algo similar sucedió en distintos grados en las otras repúblicas soviéticas, lo que podría ayudar, augura el autor, a explicar las diferencias en la interrupción de las demandas nacionales en cada caso. No se debe olvidar, advierte Marimán, que: “(...) la colonización conlleva el dislocamiento de la sociedad dominada, expresando en la ruptura entre sus sectores más formados -captación de los talentos nativos por los colonizadores - y la masa de la población" ${ }^{42}$. Añadiendo en este mismo sentido, que en el ámbito mapuche las condiciones de opresión y colonización son una variante histórica insoslayable a la hora de ahondar en esta discusión. Para este autor:

"El trato recibido por los mapuche tanto rurales como urbanos - en esta historia de incorporación e intento de asimilación al Estado-nación chileno, habla por

${ }^{39}$ AYLWIN, José. Pueblos indígenas, territorio y autonomía. Revista Pentukun. № 3. IEI. UFRO. Temuco. 1995, p. 42.

${ }^{40}$ FOERSTER, Rolf y MONTECINO, Sonia. Organizaciones, líderes y contiendas mapuche. Chile: CEM, 1988.

${ }^{41}$ MARIMAN, José. El conflicto nacionalitario y sus perspectivas de desarrollo en Chile. El caso mapuche. Denver. EEUU, 2000.

${ }^{42}$ Ibídem. 
sí misma de la discriminación (¿habrá mapuche sin historias de discriminación por los chilenos?)"43.

José Marimán indica en su argumentación, que desde la Sociedad Caupolicán, iniciado el siglo XX, hasta el Aukin Wallmapu Ngulam (Consejo de Todas las Tierras) con el cual se cerró dicho siglo, los líderes mapuche han remarcado la poca o nula credibilidad que les merecen los chilenos, y el doble estándar de sus discursos e interpelaciones tanto públicas como privadas. "Discursos que bajo el pretexto de civilizarlos, elevarlos al progreso, desarrollarlos o modernizarlos, -indica Marimán- han desatado los horrores de la pobreza y la miseria" ${ }^{44}$. Eduardo Frei Ruiz-Tagle, presidente de Chile entre 1994 y 2000, invitó por ejemplo “(...) a los mapuche-pewenche al inaugurar la central hidroeléctrica Pangue" a ser parte de este proyecto modernizador. "Pero con su programa de Área de Desarrollo Indígena no se desarrolló ningún mapuche desde el inicio al término de su gestión" 45.

De esta forma, para el historiador antes citado, la historia mapuche reviste ribetes en los cuales la marginación y represión verbal y corporal del ámbito no-mapuche sobre los mapuche, cimienta una relación en la cual el contacto y diálogo fluido resulta difícil de iniciar, toda vez que la "palabra wingka" detenta entre los mapuche una deteriorada percepción.

"Y lo que es peor,-incida Marimán con relación a Ralco- aún antes de inundarla
con las aguas de una represa, sumió a la población mapuche-pewenche de
Alto Bío-Bío en la más grave división interna que ha vivido desde la conquista
chilena. Hubo una vez allí una comunidad de personas, que hoy y luego de la
intervención de ENDESA-Frei ha sido trastocada-dislocada groseramente"46.

La contextualización de la relación interétnica entre mapuche y no mapuche, entre Estado Nacional chileno y pueblo Nación Mapuche puede ser dividida en dos grandes momentos. El hito demarcador de estos tiempos, de acuerdo a los lineamientos propuestos por mapuche como Pablo Marimán, fue el proceso por el cual el Estado chileno anexó la Araucanía a su territorio. Para este historiador, el primer momento permite caracterizar a la sociedad mapuche, por medio de "(...) profundas transformaciones ante el contacto con el elemento europeo que llega a estas tierras", las cuales “(...) influyeron

\footnotetext{
${ }^{43}$ Ibídem.

${ }^{44}$ MARIMAN, José. El conflicto nacionalitario y sus perspectivas de desarrollo en Chile. El caso mapuche. Denver. EEUU, 2000 (A).

${ }^{45} \mathrm{Ibídem.}$

${ }^{46}$ Ibídem.
} 
en el plano económico, social y político de su cultura, tendrán como contexto una situación de independencia política y expansión territorial”47.

Marimán signa como una etapa cruenta y nefasta para los mapuche, el segundo momento, aquel en el cual las tropas chilenas al mando del coronel Cornelio Saavedra y secundando por prestigiados soldados como Gregorio y Basilio Urrutia, en una estrategia de transito ordenado y sistemático siguiendo "líneas de avance", ríos primordialmente, sometieron y "redujeron" a los mapuche a un exiguo territorio para subsistir ${ }^{48}$. Fue el tiempo de la imposición cultural: “(...) y destino totalmente distinto al curso histórico que tenían los hechos hasta ese momento. Dominación y dependencia serán los nuevos elementos que cruzarán e identificarán esta etapa" ${ }^{49}$.

Antes la sociedad mapuche se organizó en torno al Wallmapu o antiguo territorio. Un espacio dejado por la deidad a los antepasados. Un sitio al que se debía preservar a toda costa. De acuerdo con José Millalén, los mapuche detentaban un sentido del tiempo histórico y de su relación con el entorno, organizado y delimitado. Indica este historiador mapuche:

"Dentro de esta amplia dimensión temporal del pasado o Kuyfi, se encuentra el Rüf kuifi em o wera füxa kuyfi dimensión que indica el pasado lejano remoto, tiempo en el cual se hallan los antecedentes fundamentales de filosofía, la religiosidad, las concepciones de fuerzas y energías que coexisten en el universo" ${ }^{50}$.

Argumentando que la lucha de Kay kay y Xeg Xeng:

“(..) trasmitido de generación en generación a través de la oralidad desde tiempos que se pierden en la inmensidad del pasado, sintetizan elementos fundamentales de la cultura y del Mapuche kimün (conocimiento mapuche ${ }^{51}$ ) y se halla presente en la memoria colectiva de la sociedad"52.

\section{Prensa chilena e imagen Mapuche}

En 1992, la visita de Juan Carlos de Borbón, Rey de España, a la ciudad de Valdivia, territorio eminentemente mapuche, generó molestias para más

\footnotetext{
${ }^{47}$ MARIMAN, Pablo. Demanda por educación en el movimiento mapuche en BELLO, Álvaro et al. Pueblos indígenas, educación y desarrollo. Santiago: CEDEM-IEI-UFRO, 1997, p. 135 (B).

${ }^{48}$ BENGOA, op. cit. (A).

${ }^{49}$ MARIMAN, op. cit., p. 135 (B).

${ }^{50}$ MILLALEN, José. La sociedad mapuche prehispánica: kimün, arqueología y etnohistoria en MARIMAN, Pablo et al. Escucha winka. Chile: Ediciones Lom, 2006, p. 23.

${ }^{51}$ Ibídem, p. 24.

${ }^{52}$ Ibídem.
} 
de alguna organización mapuche-williche tanto en Santiago como en el sur del país. Los antiguos textos de historia marcaron la tónica ${ }^{53}$. El Rey debió solicitar autorización -antes de surcar los territorios- a los jefes mapuche para ingresar a territorio no hispano. El anteriormente citado Crescente Errázuriz lo había estipulado así. Que conste:

"Un grupo de caciques tradicionales huilliches querían presentarse ante el Rey, con los bastones de cancha de plata que la Corona española les había entregado en el Tratado de La Canoas a fines de siglo dieciocho. Derecho tenían sin duda de ser recibidos", recordaba Bengoa en $1999^{54}$.

El desencuentro resultó ostensible y emblema de una compleja historia, de la cual surgió el Consejo de Todas las Tierras y su máxima figura, el werken Aucán Huilcamán, vilipendiado, perseguido, encarcelado y desacreditado líder mapuche de la década de 1990 en adelante. Desde aquel momento la Araucanía reexplotó como espacio social entrecruzado por hilos históricos disímiles y contradictorios por una parte, y férreos y excluyentes por otra. Detengámonos en un ejemplo.

En Temuco el 11 de junio de 1997 la Corporación Nacional de Desarrollo Indígena (CONADI) por medio de su Dirección Nacional firmaba un protocolo de acuerdo con distintas organizaciones mapuche, en relación con la construcción en el Alto Bío-Bío de la central hidroeléctrica Ralco. Los puntos del acuerdo fueron varios, en otros, los siguientes:

\footnotetext{
"1.- El rechazo de las Organizaciones Mapuche al informe emitido por la Comisión Nacional del Medio Ambiente, en relación con el proyecto Central Hidroeléctrica de Ralco.

2.- El rechazo al informe evacuado por la Corporación Nacional de Desarrollo Indígena a solicitud de la CONAMA por las graves implicancias de éste sobre las comunidades del Alto Bío-Bío.

3.- Que consecuencia de los informe señalados por la gravedad que tienen, las Organizaciones Mapuche han procedido a movilizarse y "tomar" las oficinas de la Dirección Nacional de la CONADI en la ciudad de Temuco, las Subdirecciones Nacionales de Iquique y Temuco, la Dirección Regional de Osorno y la Oficina de Asuntos Indígenas de Arica y Santiago" 55 .
}

\footnotetext{
${ }^{53}$ CANALES, Pedro. Tierra e Historia. Estudios y controversias acerca de la Historia Mapuche en Chile, 19502010. La Serena, Chile: ediciones Universidad de La Serena. Segunda edición, 2013, pp. 34-35.

${ }^{54}$ BENGOA, op. cit., p.195 (B).

${ }^{55}$ Acta Protocolar de acuerdo CONADI-Dirigentes Mapuches. CONADI, Temuco. 1997. Proyecto de documentación Ñuke Mapu. Disponible en: URL:http://www.soc.uu.se/mapuche
} 
Firmado por las organizaciones mapuche, los siguientes dirigentes: Mariano Melillan, Francisco Caquilpan, Nelson Porma, Víctor Naguil, Domingo Marileo, Pedro Millao. Por CONADI lo hicieron a su vez su director en aquel entonces Domingo Namancura Serrano, Víctor Alonqueo Meza Director Sub Dirección Sur y el fiscal Carlos Vargas Tapia.

No obstante lo anterior, 1998 fue el año que marcó según Jorge Iván Vergara y Andrea Aravena del Taller de Coyuntura Indígena, la aparición del conflicto violento e inquietante entre empresas forestales y comunidades mapuche. Para estos antropólogos esta situación fue inaugurada cuando a mediados de octubre de dicho año: “(...) un grupo de personas, presumiblemente mapuche, asaltó dos camionetas de Forestal Mininco y agredió a sus ocupantes" 56 . Sosteniendo con ello, que desde entonces la prensa y la televisión giraron su lente hacia la Araucanía. Para estos autores el trabajo de la prensa en general no colaboró en nada con el principio de la buena información al presentarla:

“(...) principalmente en torno a la "violencia", violencia de cual serían responsables los mapuche y, secundariamente, en torno a la "pobreza" de los afectados. Se ignoran, en general, los antecedentes de orden histórico, sociológicos y antropológicos" 57 .

Según Jorge Iván Vergara: “La organización mapuche Meli Witran Mapu en una declaración pública de 21.10.98, denunció que se habían producido situaciones similares en comunidades mapuches de Arauco, como la comunidad de Cuyinco" 58 . Agregando fehacientemente que: "Dicha comunidad habría sido objeto de diversos ataques por parte de guardias de Forestal Arauco. A esa fecha, ya se habrían producido cuatro enfrentamientos con guardias contratados por la forestal en la zona (un total de 150)" 59 . Fernando Pairican sostiene que con la quema de camiones forestales en Lumaco a fines de 1997, el movimiento mapuche habría iniciado una nueva etapa en su historia, mucho más comprometida con la autonomía y un distanciamiento concreto de la autoridad chilena ${ }^{60}$.

\footnotetext{
${ }^{56}$ VERGARA y ARAVENA, op. cit., p. 3.

${ }^{57}$ Ibídem, p. 4.

${ }^{58}$ Ibídem.

${ }^{59}$ Ibídem.

${ }^{60}$ PAIRICAN, Fernando. Lumaco: la cristalización del movimiento autodeterminista mapuche. Revista de historia social y mentalidades. № 17. USACH. 2013, pp. 36-37.
} 
Luego de aquel incidente, el 21 de diciembre de 1998, fuerzas de Carabineros:

“(..) Ingresaron al terreno de la comunidad Temulemu a incautar la madera que los mapuche habían extraído del predio en conflicto. Los comuneros solicitaron al intendente Eltit y al Gobernador de Malleco, Roberto Parant, <<pronunciarse ante esta grave situación >> y agregaron: <<le preguntamos si le interesa la vida del mapuche>>"

Posterior a este hecho, proliferó en la prensa la tesis de que del conflicto forestal comenzaba a transitar hacia la rebelión étnica, informando los diarios sobre las primeras armas encontradas en las comunidades, diciendo que el movimiento tenía apoyo externo, denunciando que el Gobierno manejaba información de que 1999 sería el año del levantamiento mapuche a la usanza Chiapas, con violentas acciones concentradas en Nueva Imperial y Villa Almagro. En febrero de ese año El Mercurio y La Tercera concentraban titulares y páginas informando del tema.

En marzo de 1999, El Mercurio, dicen Vergara y Aravena:

“(...) volvió a la carga con otro extenso reportaje sobre el conflicto de Temulemu: $<<$ El 'Fuerte Mininco'. Mapuche arrinconan a empresa forestal >>. Al domingo siguiente, aparecerá otro artículo central del cuerpo de reportajes, esta vez con el título: <<¿Parafina a la Madera? El gobierno frente al conflicto mapuche", cuando ya se habían iniciado las primeras negociaciones de solución del caso con la intermediación de la Corporación Nacional de Desarrollo Indígena"62.

Intentando con esta estrategia comunicacional: “(...) cuestionar las políticas del gobierno"63. Llegando incluso a faltar a la ética profesional, cuando el 30 de marzo, La Tercera indicaba que el conflicto ya tenía su primer muerto, reconociendo en la propia crónica que se trata de un caso absolutamente policial, noticia confirmada por el entonces Intendente del Bío-Bío, Marín Zilic.

Para Vergara y Aravena, es sistemática y bien urdida, la forma en como la prensa informa las noticias que involucran a las comunidades mapuche movilizadas. Siempre existe la aprehensión y la duda desatada. Los mapuche son acusados de tener conexiones subversivas y financiamiento externo, dejando claro que las demandas y problemas mapuche, serían injustificadas, peligrosas y artificiales. Llegando a concluir que: "Si se consideran los

\footnotetext{
${ }^{61}$ VERGARA y ARAVENA, op. cit, p. 6.

${ }^{62} \mathrm{Ibídem.}$

${ }^{63}$ Ibídem.
} 
antecedentes históricos más lejano de este y otros casos similares, obtenemos una visión diferente y más compleja que la presentada en Mininco y los medios de comunicación" ${ }^{4}$.

Indicando que las acciones de las comunidades de Traiguén, Lumaco y Lleu Lleu datan de mucho antes de la llegada de empresas forestales. En el caso de la comunidad de Temulemu, Vergara advierte:

\begin{abstract}
“(...) ésta realiza desde 1926 gestiones para obtener la restitución de tierras antiguas no incluidas en el Título de Merced /327 hás pertenecientes al Fundo Santa Rosa de Colpi) y de una parte de dicho Título que había sido ocupada por propietarios particulares (58,4 hás), sin encontrar hasta ahora una solución judicial. Sólo el periodo de la Reforma Agraria se produjo un vuelco en la situación" 65 .
\end{abstract}

Según Vergara, un segundo problema sería la explotación forestal, en su más amplio concepto. Recuerda el autor que desde fines de la década de 1970, grandes empresas comienzan a adquirir predios en Traiguén y otras zonas de la Araucanía, esto “(...) ha acelerado un proceso de empobrecimiento de los recursos naturales y materiales de las comunidades mapuche del sector", en gran medida "Por sus características (monocultivo, especie plantada, uso de pesticidas y consumo muy alto de agua de los árboles), ha terminado por prácticamente agotar los medios de subsistencia de una población ya muy pobre antes de la llegada de las forestales" ${ }^{66}$. Situación que fomenta una ya aguda historia de pauperización material entre los mapuche.

Un gesto simbólico y reivindicativo que marcó la cuestión mapuche a mediados de 1999 fue la marcha iniciada en la región de la Araucanía con dirección a Santiago. La prensa informaba que desde el 27 de mayo una marcha convocada por el Consejo de Todas las Tierras, con el objeto de hacer presentes las demandas ancestrales mapuche al Presidente de la República, se encontraba en curso, planteando la llegada a la capital cerca del 20 de junio ${ }^{67}$.

El jueves 24 de junio, el mismo diario titulaba que la marcha, ya en Santiago no pudo llegar a la Moneda, cuestión que llevó a Aucán Hulcamán a declarar que la negativa presidencial a recibirlos sería una iniciativa racista ${ }^{68}$. No siendo la única movilización de este tipo. En una de características análogas

\footnotetext{
${ }^{64}$ Ibídem.

${ }^{65}$ Ibídem.

${ }^{66} \mathrm{Ibídem.}$

${ }^{67}$ EL MERCURIO, 02.06.1999, p. 1.

${ }^{68}$ EL MERCURIO, 24.06.1999, p. 2.
} 
el 12 de octubre en Concepción, El Mercurio informaba: "Fue el mayor invento indígena de los último años. Una jornada que dejó en claro dos cuestiones: el masivo apoyo <<huinca >> a la causa aborigen y que el alcalde de Tirúa, Adolfo Millabur, ya se empina como el referente de lucha autónoma"69. Resaltando con cierta ironía que fue, sin duda alguna:

“(..) un día de paz, amor y solidaridad. En realidad, sólo unas horas en que
mapuche y no mapuche se unieron en una larga marcha pintada con una
curiosa tonalidad multiétnica y multicultural -con indígenas en clara minoría-
donde el discurso reivindicativo de los autónomos y las palabras solidarias
de los <<huincas >> se hermanaron en una fecha en que la vieja fiesta por el
descubrimiento hispano ha pasado a transformarse en una jornada de lamento
y congoja por el genocidio cultural causado por los españoles"70.

Agregando que no hubo violencia. Concepción no ardió: “(...) como muchos temían. Sólo una larga y multitudinaria caminata llena de simbolismos y un gran parque penquista colmado de una asistencia multirracial dedicada a escuchar discursos, poemas y música indígena. Casi como en un gran festival mapuche ${ }^{71}$ ".

Los oradores aquel día fueron Nicolaza Quintremán, Aucán Huilcamán y Adolfo Millabur. Cada uno de ellos, informa la prensa, alzó su voz para enaltecer y defender la causa mapuche, además de agradecer el apoyo ciudadano, nunca antes visto, según la nota. Reproduciendo palabras de uno de los oradores: "Al Gobierno ya no le pedimos nada porque está en los descuentos. Pero a ustedes sí que les pedimos que nos apoyen cuando hagamos recuperación de las tierras y que protesten cuando la autoridad nos persiga"72.

Según El Mercurio, esta marcha sirvió para redefinir aspectos de la temática y ordenamiento mapuche. Cuatro puntos definían esta cuestión, según este diario: la marcha del 12 de Octubre favoreció la imagen del Alcalde de Tirúa como nuevo referente mapuche; se consolidó la idea de que Concepción debía ser la nueva ciudad base de las reivindicaciones, relegando a Temuco a un segundo plano; el posicionamiento de Identidad Lafquenche ${ }^{73}$ (del alcalde Millabur) en conjunto con el Consejo de Todas las Tierras para

\footnotetext{
${ }^{69}$ EL MERCURIO, 17.1 0.1999, p. D36.

${ }^{70}$ Idem.

${ }^{71}$ Idem.

${ }^{72}$ Idem.

${ }^{73}$ Identidad Lafquenche: organización territorial mapuche de zona litoral de territorio mapuche. Su líder histórico es Adolfo Millabur, actual alcalde de la Comuna de Tirúa, en la región de Concepción. Lafquen en idioma mapuche se refiere precisamente a lo indicado antes, zona litoral o de costa, y lafquenche: gente del mar o litoral.
} 
acometer negociaciones con el poder central en contraposición con la radicada Coordinadora Arauco-Malleco, y la distancia que toma el movimiento mapuche de grupos no-mapuche que apoyan la causa étnica, priorizando su autonomía y libertad de acción. El diario cita al respecto a la dirigenta pehuenche Carmen Rosa Paine declarando: "Lo único que hemos tenido con Juan Pablo Orrego y los ecologistas han sido problemas. Son igual que Endesa: sacan plata y no nos ayudan en nada. Se están aprovechando de las pobres 'ñañas', pero no lo vamos a permitir"74.

Antes, en el mes de septiembre, fueron confirmados los procesamientos de cuatro mapuche involucrados en asaltos, a un campamento forestal y un incendio, según la prensa de Santiago. Informándose que en Concepción la Corte de Apelaciones: “(...) confirmó el procesamiento de cuatro mapuche dictados por los juzgados del crimen de Lebu y Cañete, a raíz de un atentado a un campamento forestal de Bosques Arauco, en Los Álamos, y del incendio y saqueo de la hacienda Lleu-Lleu, en Tirúa"75. A lo que el gobernador de Arauco en aquel momento, Carlos González añadió con tonalidad militaris: "Aquellos que instigan la violencia, lejos de representar al pueblo mapuche, perjudican gravemente sus legítimas aspiraciones"76.

Entre el 2000 y 2001 las tensiones se mantuvieron. La central Ralco comenzó a ser realidad a pesar de los actos de reivindicación y apoyo hacia los Pewenche ${ }^{77}$ del Alto Bío-Bío, de Ralco Lepoy y Quepuca Ralco. Los problemas con las empresas forestales continuaron siendo parte del cotidiano mapuche. El Juzgado de Garantía y la Fiscalía Militar, sinónimos de hostigamiento y persecución sostenida.

En el antes aludido 2001, cinco fueron los momentos más álgidos y preocupantes del conflicto protagonizado por los Mapuche, el Estado chileno y los grupos empresariales del sur. El primero se produjo en enero, cuando fue quemado una máquina retroexcavadora en el fundo El Carmen; un incendio en un campamento forestal en Collipulli; el baleo de tres agricultoras y heridas (a una niña de lonko) propinada por perdigones tras enfrentamientos entre fuerza pública y comuneros. El segundo momento, ocurrió el 29 de mayo y fue conocido como el "escándalo Conadi", cuando se abrió un sumario administrativo por petición de la entonces Ministra de Mideplan, Alejandra

\footnotetext{
${ }^{74}$ EL MERCURIO, 17.10.1999, p. D36.

${ }^{75}$ EL MERCURIO, 04.09.1999, p. C10.

${ }^{76}$ Idem.

${ }^{77}$ Mapuche de la zona cordillerana de Wallmapu o territorio mapuche.
} 
Krauss, debido al registro de sueldos millonarios en dicha corporación y compra irregular de tierras. Cabe recordar que fue la abogada Alejandra Reyes quien presentó primero las denuncias que permitieron desatar esta grave irregularidad.

El tercer momento, se registró en junio del 2001, cuando los enfrentamientos entre Carabineros y comuneros en el fundo El Ulmo camino a Curacautín generaron inquietud. Un cuarto momento, se desató con la encarcelación de Aucán Huilcamán por incidentes acaecidos meses atrás. Por último, en el mes de diciembre, se vivió un periodo complejo, incubadora de la agudización de demandas, denuncias y posturas de unos contra otros ${ }^{78}$.

La prisión se fue tornando un paisaje cada vez más común para comuneros y dirigentes mapuche tanto en la Región del Bío-Bío como en la Araucanía. Acusaciones de racismo, xenofobia y agresiones por parte de funcionarios de Carabineros y Gendarmería, fueron y son denuncias recurrentes entre los afectados de privación de libertad, de sus familias y conglomerados comunitarios. Más aún, en medios de prensa son acusados de terroristas. Los empresarios volvieron a atacar ${ }^{79}$.

Cabe consignar que los Mapuche no son gente de prisión. Todo lo contrario. Regidos por el Ad-Mapu ${ }^{80}$ ancestral, y más tarde dentro de la lógica chilena, la ley siempre fue respetada y cumplida. Por eso resulta comprensible el alto índice de jóvenes mapuche inscritos en los cantones de reclutamiento militar u otras disposiciones legales ${ }^{81}$. Es más. Cuando el Decreto-ley 2.568 acerca de la propiedad indígena, promulgado en la dictadura pinochetista en marzo de 1979, entró en vigencia, y uno de sus artículos llamaba a dividir las comunidades, los Mapuche a pesar de las objeciones y rechazos a tal mandato, lo hicieron.

La Concertación y más puntualmente el gobierno de Ricardo Lagos durante dichos años, impulsó una política denominada del "nuevo trato", la cual según palabras de José Aylwin por medio de la aplicación de la Ley Antiterrorista a comuneros mapuche aborta las declaradas -buenasintenciones, pues los juicios en este sentido tienen “(...) graves consecuencias para las garantías procesales de los acusados y pueden socavar seriamente el principio de presunción de inocencia (...)" 82 .

\footnotetext{
${ }^{78}$ DIARIO AUSTRAL, 31.12.2001, pp. A4-A6.

${ }^{79}$ EL MERCURIO, 10.03.2002.

${ }^{80}$ Leyes mapuche tradicionales.

${ }^{81}$ LEIVA, op. cit., p. 58.

${ }^{82}$ AYLWIN, op. cit., p. 41.
} 
La estrategia del gobierno de Ricardo Lagos fue iniciar un proceso de "negociación y diálogo", de acuerdo a los que indica Eduardo Mella, “(...) con algunos grupos mapuche e inmediatamente, "cerrando las filas”, una política de fuerte represión, criminalización y judicialización que se va incrementando en contra de aquellos que no aceptan sus ofertas"83.

De esta forma, la década de 1990, del 2000 y los primeros años del XXI, han resultado ser la contrapartida -para los Mapuche- de los planes de desarrollo económico e integración comercial planetaria proyectados por los últimos gobiernos. Maltrato, persecución, clandestinidad, operaciones de inteligencia destinados a descabezar el movimiento social Mapuche reciente.

\section{Conclusiones}

A partir del año 2006, con la publicación del libro Escucha winka $a^{84}$ y luego de diez años de actividad de la Coordinadora de comunidades en conflicto Arauco - Malleco (CAM), la historia de movilizaciones y debates en torno a la "cuestión mapuche" fue sumando nuevas aristas, entre ellas, la cada vez más frontal y clara demanda por autonomía y la exigencia a cumplir directrices del derecho internacional indígena, como el Convenio 169 firmado oficialmente por el estado chileno el año 2008.

En este sentido, los aspectos de continuidad que resaltan y complejiza a diario este escenario son los discursos anti indígenas que perduran y afloran a diario entre las autoridades y población chilena en general contra los mapuche, sus movilizaciones y proyectos. A nivel teórico, y a partir de la lectura de los antecedentes aquí expuestos, la ocupación y despojo de etnoterritorios no sólo fue un gesto mercantil-capitalista, sino una expresión de la "mirada de mundo" de las elites locales -que por medio del aparato estatal (leyes, instituciones, sistema educacional entre otros), los medios de prensa, y la población que no se declara indígena, y abraza en su mayoría los discursos y conductas de los colonizadores-, fueron elaborando históricamente un plan etnocida contra la población mapuche, su cultura, saberes, historia y territorialidad.

Tras el velo de la acción "civilizatoria" chilena, podemos vislumbrar una estructura de poder colonial que no ha dejado de operar, oprimir y pauperizar a la población mapuche. Ahora bien, este esquema analítico

\footnotetext{
${ }^{83}$ MELLA, op. cit., p. 110.

${ }^{84}$ Escucha winka, libro publicado por Lom, Chile, 2006. Winka es sinónimo de extranjero o no mapuche. En este sentido, este libro es un llamado a la reflexión crítica hecha por mapuche a la sociedad chilena dominante.
} 
también lo podríamos aplicar a otros pueblos indígenas que habitan dentro de los lindes oficiales del estado chileno: los aymara, quechua, likanantay y kollas en el norte del país, que bregan contra la escasez hídrica por causa de la sobre explotación minera en dichos territorios; o los pocos representantes indígenas de la zona austral, que se enfrentan a diario con la las restricciones y prohibiciones de las leyes pesqueras, o la grave falta de conectividad o inversión en infraestructura en sus lugares de residencia, todo lo anterior cruzado por una crisis profunda de las lenguas vernáculas, que comienzan a extinguirse, bajo la atenta mirada de las autoridades nacionales y regionales que prácticamente no llevan cabo políticas que reviertan esta situación.

De vuelta al análisis histórico de la situación mapuche entre 1990 y 2005, podemos consignar cinco ideas de cara al futuro que se fue perfilando.

En primer lugar, el movimiento mapuche fue distanciándose cada vez más de la figura del estado, por considerarlo "paternalista" y "cooptador" entre otras características. En segundo lugar, el movimiento mapuche si bien ha seguido siendo diverso, se ha puesto de acuerdo en tres ideas primordialmente: restitución de territorio antiguo mapuche; revitalización de la lengua madre o mapudungün, y fortalecimiento de las identidades étnicas mapuche, tanto a nivel rural como urbano. En tercer lugar, internacionalización de la "causa" mapuche. En ese sentido, destacó la demanda interpuesta en la Corte Interamericana, ganada al estado chileno por los lonkos, Pascual Pichun, fallecido el año 2013, y Aniceto Norin, por abusos y violación de derechos fundamentales. En cuarto lugar, la elaboración y puesta en común, de un diagnostico histórico mapuche, que identifica una situación de dominación de tipo colonial que no ha cesado y que reproduce relaciones de poder signadas por el peso nocivo de la diada colonizador/colonizado. Y por último en quinto lugar, la consolidación -en concordancia con el punto cuatro- de un núcleo de pensamiento mapuche, organizado en diversas instituciones de este tipo, resaltando la Comunidad de Historia Mapuche, fundada el año 2012, y cuyo fin ha sido escribir y debatir la historia nacional mapuche desde sus propios actores $^{85}$. En este escenario, la discusión en torno al colonialismo chileno, los procesos de descolonización y el trabajo intelectual mapuche ha ido copando

\footnotetext{
${ }^{85}$ La Comunidad de Historia Mapuche posee dos libros editados, que han marcado el debate de los últimos años, siendo estos los siguientes: i) Ta Iñ Fijke Xipa Rakizuameluwün/Historia, colonialismo y resistencia desde el país Mapuche, y ii) Awükan ka kuxankan zugu Wajmapu mew/Violencias coloniales en Wajmapu. Ediciones CHM. Temuco. 2015. También destacan los trabajos de jóvenes historiadores mapuche como José Luis Cabrera Llancaqueo (Machi mongen tani Santiago warria mew/Historia de un Machi en Santiago. Santiago: Ediciones GT Kuifike, 2013) y Fernando Pairican (Malón. La Rebelión del movimiento mapuche. Santiago: Ediciones Pehuén, 2014).
} 
las agendas y foros, en gran medida porque este cuadro referencial y la voz subalterna mapuche que comienza a "vislumbrarse", han ido ensanchando los límites dialógicos en Chile, encontrando frente a esto detractores y puntos de apoyo $^{86}$.

Ahora bien, y antes de cerrar este trabajo, podemos sostener que la historia post 2005 para el movimiento mapuche y la reflexión que nace desde el pensamiento propio, sigue siendo un capítulo abierto, que se proyecta como un tiempo de reencuentro mapuche, revalorización de esta identidad étnica y la proyección de esta, en la juventud y niñez que crecen y se expanden en conocimiento y reflexión, en la era de la globalización e informacionalización, a partir de los nuevos sones de pifilkas, trutrukas y kultrunes ${ }^{87}$ que suenan y recorren la historia propia y la historia "con otros".

Artigo recebido para publicação em 05/07/2016

Artigo aprovado para publicação em 09/11/2016

\footnotetext{
${ }^{86}$ Respecto del debate cruzado por el colonialismo interno/chileno, destacan trabajos de Sergio Caniuqueo, Enrique Antileo y Héctor Nahuelpan por citar algunos nombres. En el ámbitos de las intelectualidades indígenas dos trabajos son los que han abordado esta discusión: Claudia Zapata (Intelectualidades indígenas piensan América Latina. Quito: Ediciones Abya Yala, 2007) y Pedro Canales junto a Carmen Rea (Claro de luz. "Intelectualidades indígenas" y descolonización. Chile: IDEA, USACH, 2013).

${ }^{87}$ Instrumentos mapuche de viento y percusión respetivamente.
} 